\title{
Retinoic acid regulates the development of a gut-homing precursor for intestinal dendritic cells
}

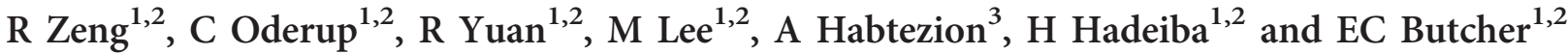

The vitamin A metabolite retinoic acid (RA) regulates intestinal immune responses through immunomodulatory actions on intestinal dendritic cells (DCs) and lymphocytes. Here, we show that RA also controls the generation of gut-tropic migratory DC precursors, referred to as pre-mucosal DCs (pre- $\mu \mathrm{DCs})$. Pre- $\mu \mathrm{DCs}$ express the gut trafficking receptor $\alpha 4 \beta 7$ and home preferentially to the intestines. They develop in the bone marrow (BM), can differentiate into CCR9 ${ }^{+}$ plasmacytoid DCs as well as conventional DCs (cDCs), but preferentially give rise to $C D 103^{+}$intestinal cDCs. Generation of pre- $\mu \mathrm{DC}$ s in vivo in the BM or in vitro is regulated by RA and RA receptor $\alpha(R A R \alpha)$ signaling. The frequency of pre- $\mu \mathrm{DCs}$ is reduced in vitamin A-deficient animals and in animals treated with RAR inhibitors. The results define a novel vitamin A-dependent, RA-regulated developmental sequence for DCs and identify a targeted precursor for $\mathrm{CD}_{103}{ }^{+} \mathrm{cDCs}$ in the gut.

\section{INTRODUCTION}

The maintenance of steady-state tolerance to commensal flora and the ability to rapidly clear pathogens in case of gut wall disruption require flexibility and sophistication in the mucosal immune system. Specialized antigen-presenting dendritic cells (DCs) in the gut wall and gut-associated lymphoid tissues (GALT) control the balance between intestinal immunity and inflammation. ${ }^{1-9}$ It is now clear that vitamin $\mathrm{A}$ and its metabolite retinoic acid (RA) play critical roles in the local differentiation and function of intestinal DCs, especially the migratory $\mathrm{CD} 103^{+}$ populations. ${ }^{10}$ RA programs $\mathrm{CD} 03^{+}$DCs to upregulate retinaldehyde dehydrogenase (RALDH), the rate-limiting enzyme for conversion of vitamin A precursors into RA. ${ }^{10}$ These mucosal DCs migrate to the draining mesenteric lymph nodes (MLNs) where they present RA along with processed antigen to T cells. ${ }^{2,4} \mathrm{RA}$ imprints responding $\mathrm{T}$ cells with gut-homing properties ${ }^{11}$ and, in the absence of danger signals, favors the induction of tolerogenic regulatory $\mathrm{T}$ cells ${ }^{8}$ by suppressing memory/effector T-cell-mediated inhibition of Treg conversion from naive T cells. ${ }^{12}$ Thus, RA plays a critical local role in intestinal DC function and immune regulation, but its involvement in the origin of intestinal DC precursors has not been studied.

Here, we describe a targeted gut-homing DC precursor, designated pre-mucosal DCs (pre- $\mu \mathrm{DCs}$ ), whose development in the bone marrow (BM) is regulated by RA. Pre- $\mu$ DCs are identifiable phenotypically as lineage ${ }^{-} \mathrm{CD} 11 \mathrm{c}^{\text {int }} \mathrm{B} 220^{+}$ $\mathrm{CCR}^{-}$cells that express the intestinal-homing receptor $\alpha 4 \beta 7$. They can arise in vitro from $\mathrm{CD} 11 \mathrm{c}^{\mathrm{int}} \mathrm{B} 220^{+} \mathrm{BM}$ precursors that lack both CCR 9 and $\alpha 4 \beta 7$. Pre- $\mu$ DCs give rise to $\mathrm{CCR}^{+}$plasmacytoid DCs (pDCs) and to conventional DCs (cDCs), and home preferentially to the intestines in vivo. They are particularly efficient at generating $\mathrm{CD}_{103}{ }^{+} \mathrm{cDCs}$ in vitro and replenishing intestinal $\mathrm{CD} 103^{+} \mathrm{cDCs}$ in vivo. RA signaling through RA receptor $\alpha$ (RAR $\alpha)$ drives pre- $\mu \mathrm{DC}$ differentiation from BM progenitors, and the frequency of pre- $\mu$ DCs was reduced in vitamin A-deficient animals and in animals treated with an inhibitor of RAR signaling. RA thus plays a unifying role in intestinal DC development and function, regulating both the generation of gut-homing precursors and the specialized functions of DC within the gut environment.

\section{RESULTS \\ Identification of a phenotypically unique $\alpha 4 \beta 7^{+}$DC subset in vivo}

In studies of DC subsets expressing B220, we discovered a subset of $\mathrm{B} 220^{+} \mathrm{CD} 11 \mathrm{c}^{\text {int }} \mathrm{DCs}$ that expresses the $\alpha 4 \beta 7$ integrin, a homing receptor that mediates lymphocyte recruitment into the intestinal wall through interaction with the mucosal

\footnotetext{
${ }^{1}$ Laboratory of Immunology and Vascular Biology, Department of Pathology, Stanford University School of Medicine, Stanford, California, USA. ${ }^{2}$ The Center for Molecular Biology and Medicine, Veterans Affairs Palo Alto Health Care System, Palo Alto, California, USA and ${ }^{3}$ Department of Medicine/Gastroenterology, Stanford University School of Medicine, Stanford, California, USA. Correspondence: R Zeng (ruizhuz@stanford.edu); EC Butcher (ebutcher@stanford.edu)
} 
vascular addressin MAdCAM1 ${ }^{13}$ (Figure 1a; Supplementary Figure S1a online). $\alpha 4 \beta 7^{+}$B $220^{+}$DCs are found in secondary lymphoid tissues and the $\mathrm{BM}$, and are particularly prominent among the $\mathrm{B} 220^{+}$DCs in the gut-associated MLN and in the small intestine (SI) lamina propia (LP) (Figure 1a; Supplementary Figure S1a online). These cells are phenotypically distinct from previously described peripheral or BM DC populations or precursors, including splenic $\mathrm{CDCs}$, $\mathrm{BM} \mathrm{CCR9}^{+}$pDCs, common DC progenitors (CDPs), and precDCs (Supplementary Figure S1b and c online). We took advantage of an Fms-like tyrosine kinase 3 ligand (Flt3L)expressing B16 melanoma to expand DC subsets in vivo with minimal alterations in their phenotypic or functional capabilities for homing and adoptive transfer studies. ${ }^{14}$ The $\alpha 4 \beta 7^{+}$B220 ${ }^{+}$DCs were dramatically expanded in Flt3Ltreated mice, suggesting a proliferative or progenitor potential (Figure 1b). We refer to them hereafter as pre- $\mu \mathrm{DCs}$, short for pre-mucosal DCs.

We hypothesized that, by virtue of their expression of $\alpha 4 \beta 7$, pre- $\mu$ DCs might home efficiently from the blood into the gut wall. Pre- $\mu \mathrm{DCs}$ were sorted from lymphoid tissues of Flt3Ltreated B6.CD45.2 mice. Localization in vivo was assessed 3 days after intravenous transfer into congenic B6.CD45.1 recipients. Pre- $\mu$ DCs preferentially homed to the SI LP (Figure 1c). Preferential homing of pre- $\mu$ DCs to the SI LP and colon was also apparent in shorter-term $(12 \mathrm{~h})$ homing studies (data not shown).

\section{Pre- $\mu \mathrm{DCs}$ give rise to $\mathrm{CCR}^{+} \mathrm{pDCs}$ and to $\mathrm{CD} 103^{+} \mathrm{CDCs}$ in vitro}

To assess the progenitor potential of pre- $\mu \mathrm{DCs}$, we sorted them from $\mathrm{BM}$ and cultured them in vitro with total $\mathrm{BM}$ cells taken from CD45 allotype congenic mice as feeder cells (Figure 2a). In some experiments, we also used pre- $\mu$ DCs sorted from the $\mathrm{BM}$ of Flt3L-treated mice; these cells are phenotypically similar to normal $\mathrm{BM}$ pre- $\mu \mathrm{DCs}$, the classical CCR9 ${ }^{+}$pDC markers PDCA1, Siglec H, and Ly6c are downregulated, not unlike the surface phenotype of pre- $\mu$ DCs in normal spleen (see Figure 4a). Cells were cultured with recombinant Flt3L and their progeny were analyzed by flow cytometry after 3-6 days. By days 3-4, the cultures contained three prominent and phenotypically distinctive pre- $\mu \mathrm{DC}$-derived populations (Figure $\mathbf{2 b}$ and $\mathbf{c}$ ): $\mathrm{CCR}^{+}$pDCs, which retained high levels of B220 and intermediate expression of CD11c; $\mathrm{CD}_{103}{ }^{+}$DCs that were $\alpha 4 \beta 7^{-} \mathrm{CCR}^{-} \mathrm{B}_{22}{ }^{-}$and $\mathrm{CD} 11 \mathrm{c}^{+}$, essentially a cDC phenotype; and a population of $\alpha 4 \beta 7^{+}$pre$\mu D C$-like cells whose phenotype (lower B220 and slightly higher CD11c levels than starting pre- $\mu$ DCs) appeared transitional between that of BM pre- $\mu D C s$ and $c D C s$. In fact, a fraction of the $\alpha 4 \beta 7^{+}$DC had upregulated CD103. By day 6 , pre- $\mu$ DC-derived progeny were mostly $\mathrm{CD}_{103}{ }^{+} \mathrm{cDC}$ $(70-80 \%, N>3)$ (Figure 2c). However, the absolute numbers of all three subsets peaked on day 3 and decreased by day 6 , suggesting limited life span of pre- $\mu \mathrm{DC}$ and their progeny in vitro (Supplementary Figure S2a online). Similar results were seen whether pre- $\mu$ DCs were from normal or Flt3L-
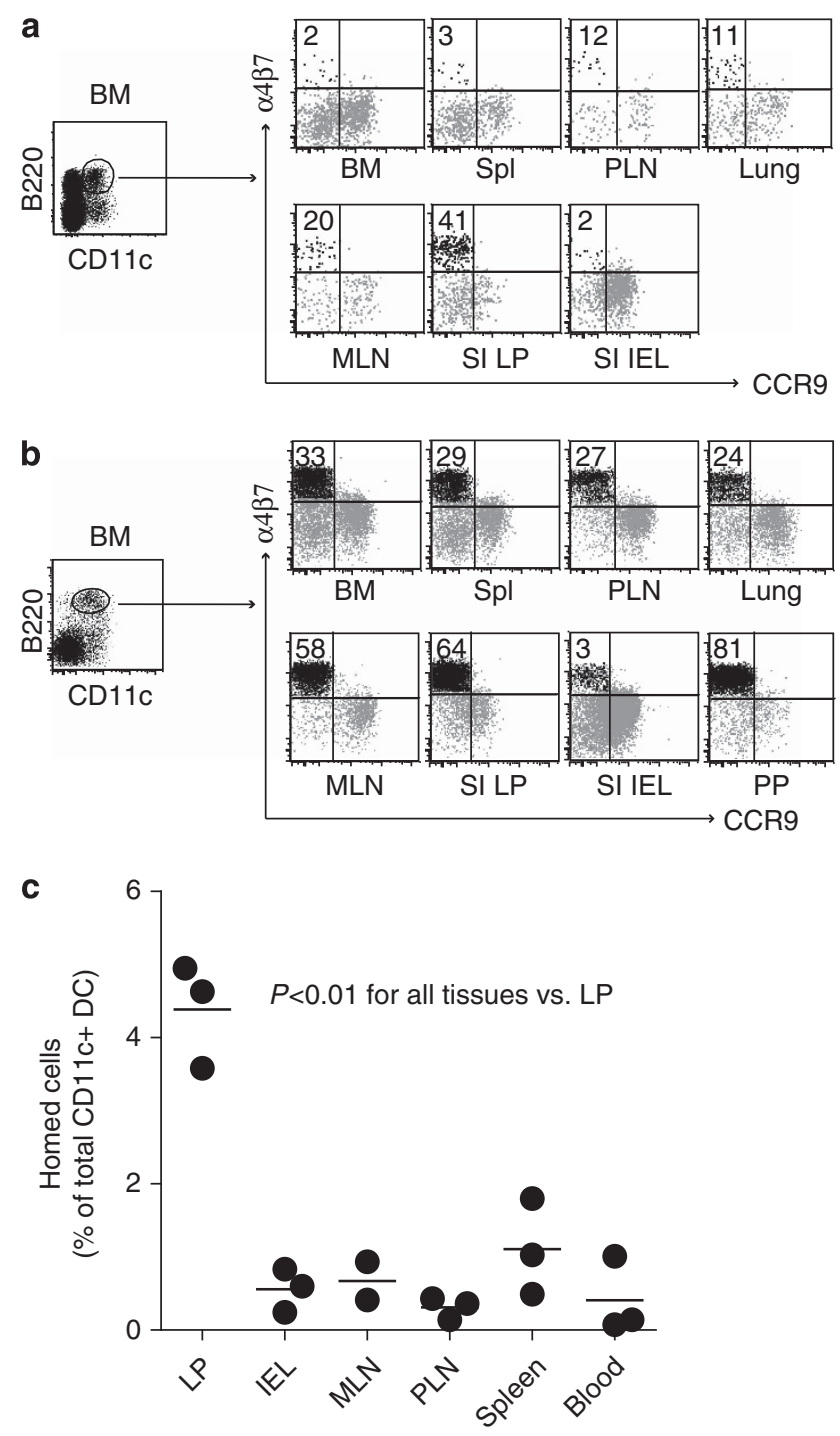

Figure 1 Identification of a phenotypically unique $\alpha 4 \beta 7$ expressing, guthoming dendritic cell (DC) subset in vivo. (a) Surface expression of $\alpha 4 \beta 7$ and CCR9 on live lin ${ }^{-}$CD11C ${ }^{+} \mathrm{B}_{220^{+}}$DCs from lymphoid and nonlymphoid tissues from 2- to 3-week-old C57BI/6 mice; lin indicates CD3, CD19, and NK1.1. Data are representative of seven independent experiments. (b) Surface expression of $\alpha 4 \beta 7$ and CCR9 on live $\mathrm{lin}^{-} \mathrm{CD} 11 \mathrm{C}^{+} \mathrm{B} 22 \mathrm{O}^{+} \mathrm{DCs}$ from lymphoid and nonlymphoid tissues taken from Fms-like tyrosine kinase 3 ligand (Flt3L)-treated mice. Data are representative of at least three independent experiments. (c) Three million purified pre- $\mu \mathrm{DCs}$, sorted from peripheral lymphoid tissues from Flt3Ltreated B6.CD45.2 mice, were transferred intravenously into B6.CD45.1 recipients. Tissues were harvested on day 3 after transfer and donorderived cells were quantified. Data are presented as the percentage of total CD11c ${ }^{+}$host cells. Each dot represents 1 individual animal, $n=3$ from two independent experiments. $P<0.01$ for lamina propia (LP) vs. all other tissues by Student's $t$-test.

treated mouse BM (Figure $\mathbf{2 b}$ and $\mathbf{c}$ ). Consistent with prior studies of Flt3L-driven in vitro BM-derived $\mathrm{cDC}$, pre- $\mu \mathrm{DC}$ progeny in vitro did not express surface $\mathrm{CD} 8 \alpha$ (data not shown). The results demonstrate that pre- $\mu \mathrm{DCs}$ can give rise rapidly to both classical CCR ${ }^{+}$pDCs and to $\mathrm{CD} 103^{+}$cDCs. We were unsuccessful in efforts to evaluate pre- $\mu \mathrm{DC}$ development at the clonal level and therefore cannot 
a

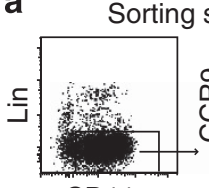

CD11c

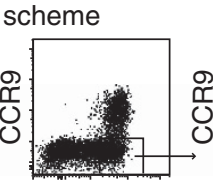

B220

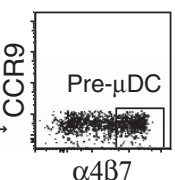

$\alpha 4 \beta 7$

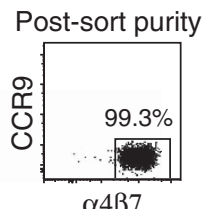

$\alpha 4 \beta 7$

b Cultured pre- $\mu \mathrm{DC}$ s sorted from normal BM

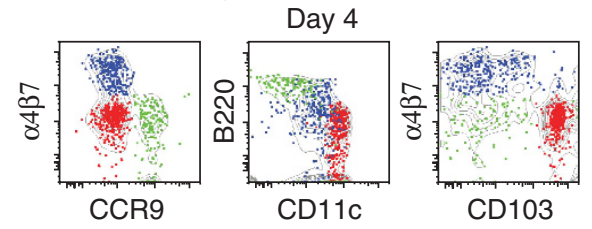

C Pre- $\mu \mathrm{DC}$ s sorted from Flt3L-treated BM
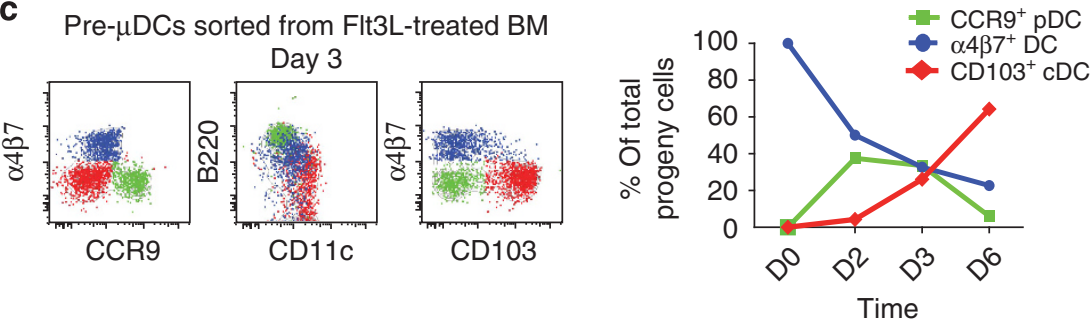

Figure 2 Pre- $\mu \mathrm{DCs}$ give rise to $\mathrm{CCR} 9^{+}$plasmacytoid DCs (pDCs) and to $\mathrm{CD} 103^{+}$conventional DCs (cDCs) in vitro. (a) Sorting scheme and purity analysis for pre- $\mu \mathrm{DC}$ s. Lin indicates CD3, CD19, and NK1.1. (b) Pre- $\mu$ DCs were sorted from bone marrow (BM) of B6.CD45.2 mice and cultured with total BM taken from congenic B6.CD45.1 mice in complete RPMI supplemented with $100 \mathrm{ng} / \mathrm{ml} \mathrm{rFlt} 3 \mathrm{~L}$. Cultured cells were analyzed by flow cytometry on day 4. Pre- $\mu$ DC-derived cells on day 4 included three distinct populations: CCR9 ${ }^{+}$DCs (green), CD103 ${ }^{+}$DCs (red) and $\alpha 4 \beta 7^{+}$DCs (blue). Gray contour plots show all pre- $\mu \mathrm{DC}$-derived cells. Data represent one of the three independent experiments with similar results. (c) Pre- $\mu \mathrm{DCs}$ were sorted from Flt3L-treated mouse BM and cultured in the conditions described in (b). Pre- $\mu$ DC-derived cells on day 3 consist of three populations similar to those from untreated mice. Line graphs show that by day 6 , most pre- $\mu$ DC-derived CCR9 ${ }^{+}$pDCs disappeared and the cultures consisted mostly of $\mathrm{CD}_{103}{ }^{+} \mathrm{cDCs}$. Data are representative of three independent experiments with similar results. DC, dendritic cell; Flt3L, Fms-like tyrosine kinase 3 ligand.

exclude the possibility that distinct $\mathrm{pDC}$ and $\mathrm{cDC}$ precursors exist within the gut-tropic pre- $\mu$ DC pool.

\section{Pre- $\mu \mathrm{DCs}$ give rise to $\mathrm{CCR9}{ }^{+} \mathrm{pDCs}$ and to $\mathrm{CD} 103^{+} \mathrm{cDCs}$ in vivo}

We next assessed the development of pre- $\mu \mathrm{DC}$ in vivo in a homeostatic setting. We sorted pre- $\mu D C$ s from Flt3L-treated B6.CD45.2 mice and injected them into congenic B6.CD45.1 recipients. Recipient mice were killed on day 4 or 7 . On day 4 after transfer, both $\mathrm{cDCs}$ and CCR9 ${ }^{+}$pDCs were observed among CD $45.2^{+}$pre- $\mu \mathrm{DC}$-derived progeny cells in the spleen, small intestine, and lung. In the intraepithelial lymphocytes (IEL), $\mathrm{CCR}^{+}{ }^{+} \mathrm{pDCs}\left(\mathrm{CD} 11 \mathrm{c}^{\mathrm{int}} \mathrm{B} 220^{+} \mathrm{CCR}^{+}\right)$predominated among pre- $\mu \mathrm{DC}$-derived cells (Figure $3 \mathbf{a}$, left). In the SI LP, a subset of transferred cells maintained the pre- $\mu \mathrm{DC}$ phenotype $\left(\alpha 4 \beta 7^{+}, \mathrm{CD}_{103^{-}}\right)$, with some showing reduced B220 expression (Figure 3a, right). Pre- $\mu D C$ progeny in the SI $\mathrm{LP}$ and in other tissues analyzed were mainly $\mathrm{CD} 103^{+} \mathrm{cDCs}$ (mucosal tissues) or CD8 $\alpha^{+}$cDC (in the spleen) on both days 4 and 7 (Figure $3 \mathbf{b}$ and data not shown). By day 7 , most pre- $\mu \mathrm{DC}$ derived $\mathrm{CCR}^{+} \mathrm{pDCs}$ and pre- $\mu \mathrm{DC}$ themselves had disappeared from all tissues, suggesting rapid turnover of pre- $\mu \mathrm{DC}$-derived $\mathrm{CCR}^{+}{ }^{+}$pDCs and a limited self-renewal capacity of pre- $\mu D C s$. Consistent with their preferential homing to the SI LP, a higher percentage of cDCs in the SI LP than in the spleen or the lung originated from pre- $\mu$ DCs
(Figure 3c). Similar results were seen in lethally irradiated recipients (Supplementary Figure S2b online). Intestinal $\mathrm{CD} 103^{+} \mathrm{cDCs}$ comprise two distinct subsets: $\mathrm{CD}^{-} 1 \mathrm{~b}^{+}$and $\mathrm{CD} 11 \mathrm{~b}^{-}$. Pre- $\mu \mathrm{DC}$ s gave rise to both $\mathrm{CD} 103^{+} \mathrm{CD} 11 \mathrm{~b}^{-}$and $\mathrm{CD}_{103}{ }^{+} \mathrm{CD}_{11 b^{+}}$intestinal cDCs in the SI LP (Figure 3b and d). The intestinal $\mathrm{CD}_{103}{ }^{+} \mathrm{CD}_{11} \mathrm{~b}^{-} \mathrm{cDCs}$ are developmentally related to the splenic $\mathrm{CD} 8 \mathrm{a}^{+} \mathrm{CD} 11 \mathrm{~b}^{-}$ cDCs, as their development depends on common transcription factors. ${ }^{15,16}$ No developmental equivalent of the intestinal $\mathrm{CD}_{103}{ }^{+} \mathrm{CD} 11 \mathrm{~b}{ }^{+} \mathrm{cDCs}$ have been identified in the spleen. Most of the pre- $\mu \mathrm{DC}$-derived CD $8 \alpha^{+} \mathrm{CD} 11 \mathrm{~b}^{-}$ cDCs in the spleen expressed a low level of CD103 (data not shown). Bogunovic et al. ${ }^{2}$ have shown that migratory pre-cDC (Lineage ${ }^{-} \mathrm{CD} 11 \mathrm{c}^{+} \mathrm{MHCII}^{-} \mathrm{CD} 135^{+}$Sirp $\alpha^{\text {low }}$ ) can also give rise to $\mathrm{CD} 103^{+} \mathrm{cDC}$ in the SI LP. When co-transferred with pre-cDC, pre- $\mu D C$ are 7 - to 10 -fold better than pre-cDC at giving rise to $\mathrm{CDC}$ in the SI LP on a per cell basis (Supplementary Figure S2c online). This is not surprising because unlike pre- $\mu \mathrm{DC}$, pre-cDC do not express gut-specific homing receptors and thus are not primed to repopulate the intestines (see Supplementary Figure S1c online).

Few pre- $\mu$ DC-derived cells were seen in the MLN 4 days after transfer but by day 7 , significant fractions of $\mathrm{CD} 103^{+} \mathrm{CD} 11 \mathrm{~b}^{-}$ and $\mathrm{CD}_{103}{ }^{+} \mathrm{CD} 11 \mathrm{~b}^{+} \mathrm{cDCs}$ in the MLN were derived from pre- $\mu$ DCs (Figure 3d). Given preferential homing of pre- $\mu D C$ to the LP rather than the MLN, pre- $\mu$ DCs likely differentiate 

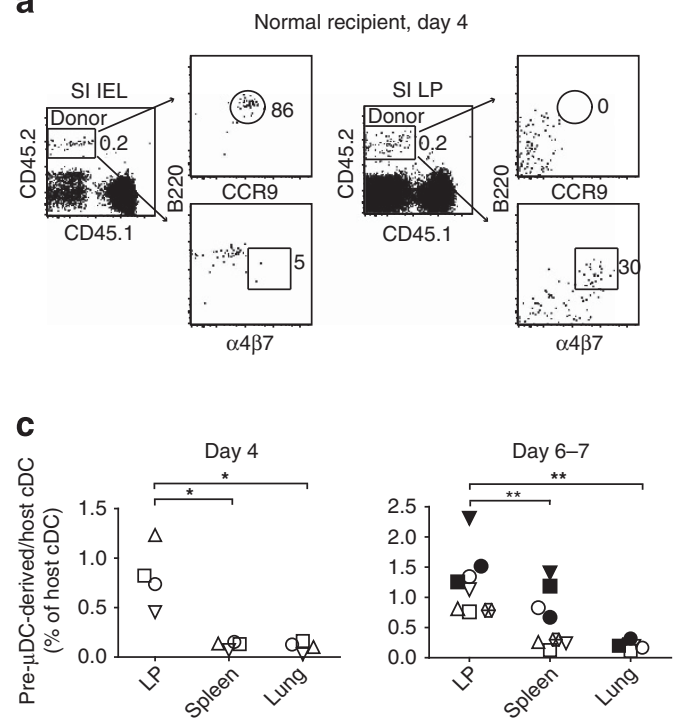

b

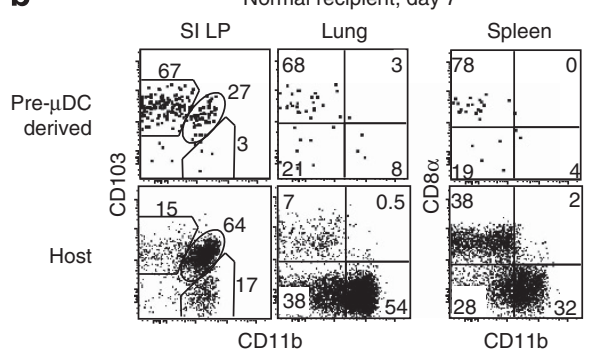

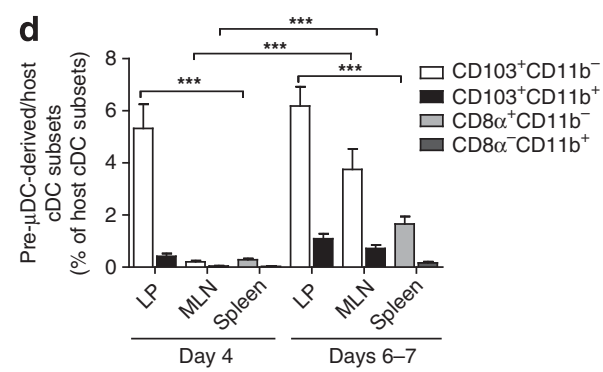

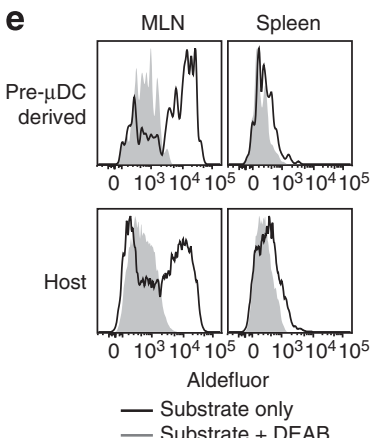

f

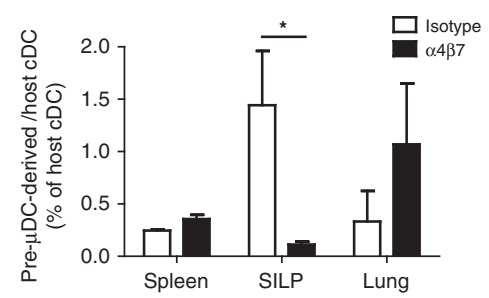

- Substrate only

Figure 3 Pre- $\mu \mathrm{DCs}$ give rise to $\mathrm{CD}_{103^{+}}$conventional DCs (cDCs) and to CCR9 ${ }^{+}$plasmacytoid $\mathrm{DC}$ (pDC) in vivo and preferentially reconstitute the small intestine. One to 2.5 million FACS-sorted pre- $\mu$ DCs (CD45.2) were injected into CD45.1 recipients and analyzed on day 4 and day 6 or 7 . Day 4: $n=4$ from two independent experiments. Day 6 or $7: n=8$ from five independent experiments. ${ }^{\star} P<0.05,{ }^{* \star} P<0.01,{ }^{\star * \star} P<0.001$ by Student's $t$-test. (a) CCR9, $\alpha 4 \beta 7$, and B220 expression on total pre- $\mu$ DC-derived cells (CD45.2) in small intestine (SI) intraepithelial lymphocyte (IEL) (left) and lamina propia (LP) (right) on day 4 after transfer. Numbers indicate percentage cells. Data shown are from one of the four recipients with similar results. (b) CD103 and CD11b on pre- $\mu$ DC-derived CD11c ${ }^{+}$cells and host CD11c ${ }^{+}$cells on day 7 . The plot shows data from one of the eight recipients with similar results. (c) Pre- $\mu \mathrm{DC}$-derived $\mathrm{CD} 11 \mathrm{c}^{+}$cells (per million input cells) as percentage of host CD11c ${ }^{+}$cells in different tissues on day 4 and day 6 or 7 . Symbols of the same shape and color represent tissues from the same animal. (d) Pre- $\mu$ DC-derived CD103 ${ }^{+}$CD11b ${ }^{-}$and $\mathrm{CD}_{103}{ }^{+} \mathrm{CD}_{11 \mathrm{~b}}{ }^{+} \mathrm{CDCs}$ from SI LP or mesenteric lymph node (MLN) and CD8 $\alpha^{+} \mathrm{CD} 11 \mathrm{~b}^{-}$and CD8 $\alpha^{-} \mathrm{CD} 11 \mathrm{~b}^{+} \mathrm{CDCs}$ from spleen are shown as percentage of the corresponding subset from the host on day 4 and day 6 or 7 after transfer. (e) Aldefluor staining of pre- $\mu \mathrm{DC}$-derived and host CD11 ${ }^{+}$ $\mathrm{cDC}$ from MLN and spleen. Negative control staining in the presence of aldehyde dehydrogenase (ALDH) inhibitor DEAB is shown for comparison. Data are representative of three independent experiments with similar results. (f) Pre- $\mu \mathrm{DCs}$ were sorted from Fms-like tyrosine kinase 3 ligand (FIt3L)-treated mice and pre-incubated with $250 \mu \mathrm{g}$ of either $\alpha 4 \beta 7$-blocking antibody (DATK32) or isotype control for 10 min at room temperature before transfer into congenic recipients. Recipient mice received $250 \mu \mathrm{g}$ of $\alpha 4 \beta 7$-blocking antibody or isotype control every $12 \mathrm{~h}$ and were killed on day 4 . Pre- $\mu \mathrm{DC}$ derived total $\mathrm{CD}_{11 \mathrm{c}^{+}}$cells were calculated as percentage of host $\mathrm{CD} 11 \mathrm{c}^{+}$cells. Data show combined results from analyses of three mice from two independent experiments. Error bars show s.e.m. ${ }^{\star} P<0.05$ by Student's $t$-test. DC, dendritic cell.

into $\mathrm{CD}_{103^{+}}$mucosal DCs in the gut wall and subsequently migrate to the MLN. This is consistent with the known migratory behavior of small intestine $\mathrm{CD}_{103}{ }^{+} \mathrm{cDCs}^{17}$ Importantly, pre- $\mu \mathrm{DC}$-derived $\mathrm{cDCs}\left(\mathrm{CD} 11 \mathrm{c}^{+} \mathrm{MHCII}^{+}\right.$ $\mathrm{B} 220^{-} \mathrm{CD}_{103}{ }^{+} \mathrm{CD}_{11 \mathrm{~b}}{ }^{+}$or $\left.\mathrm{CD} 11 \mathrm{~b}^{-}\right)$in GALT displayed the characteristic aldehyde dehydrogenase (ALDH) activity of endogenous $\mathrm{CD}_{103}{ }^{+}$gut cDCs: $\sim 50 \%$ of pre- $\mu \mathrm{DC}$-derived cDCs in the MLN stained strongly with Aldefluor (Figure 3e), a fluorogenic substrate used to detect ALDHs important in the metabolism of retinal to RA. ${ }^{18}$ In contrast, pre- $\mu$ DCs in the BM (data not shown) and pre- $\mu$ DC-derived splenic $\mathrm{cDC}$ did not display ALDH activity (Figure $3 \mathbf{e}$ ). Thus, pre- $\mu \mathrm{DCs}$ give rise to both $\mathrm{CD} 11 \mathrm{~b}^{+}$and $\mathrm{CD} 11 \mathrm{~b}^{-}$subsets of $\mathrm{CD} 103^{+} \mathrm{cDC}$ in the SI LP and acquire mucosal characteristics in response to the intestinal or GALT environment. Furthermore, antibody blockade of $\alpha 4 \beta 7$ during pre- $\mu \mathrm{DC}$ transfer drastically reduced the number of pre- $\mu D C$-derived $\mathrm{CDC}$ in the LP, but not in the spleen or lung (Figure 3f), consistent with an important role for $\alpha 4 \beta 7$-mediated homing in the pre- $\mu \mathrm{DC}$ contribution to the intestinal DC pool.

$\mathrm{CD} 11 \mathrm{c}^{\text {int }} \mathrm{B} 220^{+}$DCs were comprised of $\alpha 4 \beta 7^{+}$pre- $\mu \mathrm{DCs}$, $\mathrm{CCR}^{+}$pDCs, and a subset of $\alpha 4 \beta 7^{-} \mathrm{CCR}^{-}$(double- 
negative or DN) cells (Figure 1; Supplementary Figure S3a online). The DN DCs are particularly abundant relative to pre$\mu \mathrm{DCs}$ in the BM. When cultured in vitro with Flt3L, DN DCs gave rise rapidly (within $24 \mathrm{~h}$ ) to CCR9 ${ }^{+}$pDCs and to $\alpha 4 \beta 7^{+}$ pre- $\mu$ DCs (Supplementary Figure S3b online). Although both DN DCs and pre- $\mu$ DCs gave rise to CCR9 ${ }^{+}$pDCs in vitro, DN DCs did so more rapidly and resulted in a higher proportion of $\mathrm{CCR}^{+}{ }^{+}$pDCs (compare Supplementary Figure S3b online and Figure $\mathbf{2 b}$ and $\mathbf{c}$ ). In contrast, sorted CCR9 ${ }^{+}$pDCs retained their phenotype in culture, indicating that these cells were terminally differentiated (data not shown). Like pre$\mu \mathrm{DCs}$, upon longer culture DN DCs developed into cDCs, including $\mathrm{CD}_{103}{ }^{+} \mathrm{cDC}$, although $\mathrm{cDC}$ development from DN DCs was delayed relative to that from pre- $\mu D C s$ (Supplementary Figure S3c online). When transferred into normal or irradiated recipients, DN DCs were slightly less efficient than pre- $\mu \mathrm{DC}$ at generating $\mathrm{cDCs}$ in lymphoid tissues and did not preferentially contribute to intestinal vs. splenic cDC populations at the time points examined (days 5-7, Supplementary Figure S3d online). These results suggest that pre- $\mu \mathrm{DCs}$ arise from DN DCs in the BM, but that pre- $\mu \mathrm{DCs}$ may be more developmentally primed to migrate and reconstitute peripheral tissues, especially the intestinal tract, than are DN DCs.

\section{Intestinal pre- $\mu \mathrm{DC}$ s display a transitional phenotype but retain progenitor activity}

Pre- $\mu$ DCs are most highly represented within the GALT and SI LP of those tissues evaluated. Compared with BM pre- $\mu$ DCs, pre- $\mu \mathrm{DCs}$ in the LP displayed higher expression of CD11c, but lower or no expression of pDC markers including B220, PDCA1, Ly6C, and Siglec H (Figure 4a). LP pre- $\mu$ DCs also appeared more mature than their BM counterparts, with higher MHCII, CD11b, $\alpha 4 \beta 7$, and CCR6 expression but similar CD80 and CD86 co-stimulatory molecule expression (Figure 4a). Splenic pre- $\mu D C s$ had an intermediate phenotype (Figure 4a). When cultured with Flt3L and total BM cells, SI LP pre- $\mu$ DCs retained the ability to generate $\mathrm{CD} 103^{+} \mathrm{cDCs}$; but they displayed little or no potential to give rise to $\mathrm{pDCs}$ (Figure $4 \mathrm{~b}$ ). Furthermore, $\sim 30 \%$ of LP pre- $\mu \mathrm{DC}$ expressed proliferating cell nuclear antigen and transferred pre- $\mu \mathrm{DC}$ can still be detected 4 days after transfer, suggesting that pre- $\mu$ DCs can proliferate locally in the SI LP (data not shown and Figure 3a). We conclude that pre- $\mu D C$ in the LP retain $\mathrm{cDC}$ progenitor activity, but have a transitional phenotype likely reflecting their programmed development into $\mathrm{CD}_{103}{ }^{+}$intestinal cDCs.

\section{RA controls pre- $\mu \mathrm{DC}$ development in the $\mathrm{BM}$}

We next asked whether RA regulates the development of $\alpha 4 \beta 7^{+}$pre- $\mu \mathrm{DCs}$ from BM progenitors. Addition of RA to cultures of total BM dramatically increased the frequency of pre- $\mu \mathrm{DCs}$ among total progeny cells at the expense of CCR9 ${ }^{+}$ pDCs and DN DCs (Figure 5a and $\mathbf{b}$ and data not shown). Consistent with a requirement for RA signaling through its nuclear receptor RAR $\alpha$, pre- $\mu$ DC generation was also enhanced by the selective RAR $\alpha$ agonist AM580 (Figure 5a and $\mathbf{b}$; Supplementary Figure S4a online). When cultured with delipidated serum, which is free of retinoids, fewer pre$\mu \mathrm{DC}$ were generated. When RA or AM580 was added to the culture with delipidated serum, pre- $\mu \mathrm{DC}$ generation was enhanced (Supplementary Figure S4b online). Furthermore, addition of the pan-RAR inverse agonist BMS493 or pan antagonist LE540 inhibited pre- $\mu$ DC development in vitro (Figure $\mathbf{5 a}$ and $\mathbf{b}$ and data not shown). Like pre- $\mu \mathrm{DC}$ found in the BM in vivo, pre- $\mu \mathrm{DC}$ generated in vitro with or without RAR signaling are mostly $\mathrm{CD}_{103}{ }^{-}$(Supplementary Figure S4c online). To assess the involvement of proliferation in these effects, we labeled BM with carboxyfluorescein diacetate succinimidyl ester (CFSE) prior to culture. Under control conditions or with the RAR antagonist, a significant fraction of developing CCR9 ${ }^{+}$pDCs were derived from cells that had divided, but RA or the RAR $\alpha$ agonist almost completely eliminated this population of previously divided CCR ${ }^{+}$pDCs (Figure 5). Given the limited self-proliferative potential of CCR9 ${ }^{+}$pDCs, it is likely that RAR signaling directly inhibits $\mathrm{CCR} 9^{+}$pDC development from progenitors in the $\mathrm{BM}$. In contrast, $\mathrm{RA}$ signaling enhanced the percentage of $\alpha 4 \beta 7^{+}$pre- $\mu$ DCs arising from dividing cells (Figure 5c). Thus, RA regulates the generation of pre- $\mu \mathrm{DC}$.

Manipulation of the RAR signaling pathway had similar effects on pre- $\mu \mathrm{DC}$ development in vivo. Mice treated with RA and AM580 displayed an increase in pre- $\mu \mathrm{DC}$ frequency in the $\mathrm{BM}$, consistent with our in vitro observations. In contrast, treatment with BMS493 reduced the frequency of pre- $\mu$ DCs (Figure 5d). More importantly, pre- $\mu \mathrm{DCs}$ were also significantly reduced in the $\mathrm{BM}$ of mice fed a vitamin A-deficient diet compared with mice fed a control diet (Figure 5d). We conclude that vitamin $\mathrm{A}$ and its metabolite RA regulate the development of a targeted precursor for intestinal DCs.

\section{DISCUSSION}

We have identified a migratory common DC precursor that preferentially homes to the gut wall and gives rise to intestinal DCs, especially $\mathrm{CD} 103^{+}$subsets. Pre- $\mu \mathrm{DCs}$ have an immature phenotype and share phenotypic features with CCR ${ }^{+}$pDCs, including expression of pDC markers such as PDCA1, Siglec $\mathrm{H}$, Ly6C, and B220, but are distinguished from $\mathrm{CCR}^{+}{ }^{+}$pDCs by differential trafficking receptor expression and by their developmental potential. Pre- $\mu D C s$ express $\alpha 4 \beta 7$ but not CCR9 and proliferate and differentiate into $\mathrm{CDCs}$ and CCR9 ${ }^{+}$ pDCs in vitro and in vivo, whereas conventional CCR ${ }^{+}$pDCs are $\alpha 4 \beta 7^{-}$and are terminally differentiated. BM pre- $\mu \mathrm{DCs}$ are closely related to and can arise from $\mathrm{CD} 11 \mathrm{c}^{\mathrm{int}} \mathrm{B} 220^{+} \mathrm{CCR}^{-}$ $\alpha 4 \beta 7^{-}$DN DCs.

Development of pre- $\mu$ DCs in the BM is regulated by RA. Treatment of BM cultures with RAR agonists increased and RAR antagonists decreased the frequency of pre- $\mu$ DCs. All trans-RA, a pan-RAR agonist, and AM580, an RAR $\alpha$-specific agonist, had similar effects on pre- $\mu \mathrm{DC}$ development, suggesting that modulation of RAR signaling in the BM is primarily through RAR $\alpha$. RAR signaling had a similar modulating effect on pre- $\mu \mathrm{DC}$ development in vivo. Vitamin A deficiency, which 

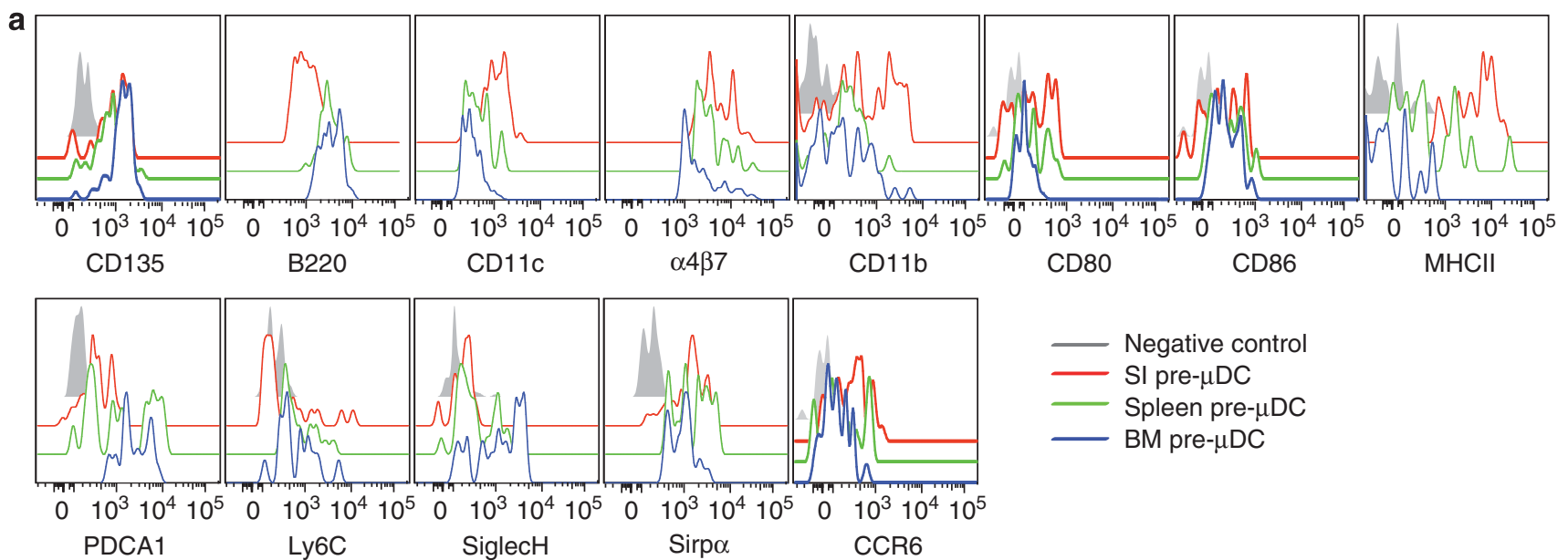
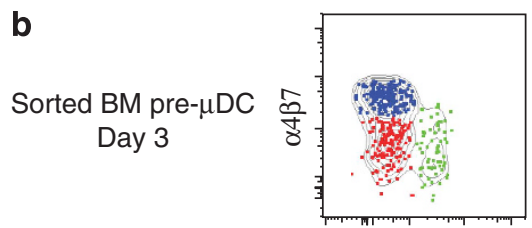

CCR9

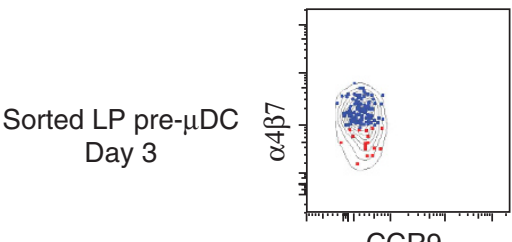

CCR9

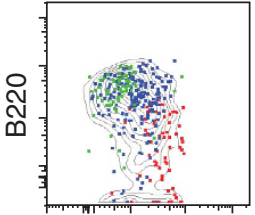

CD11C

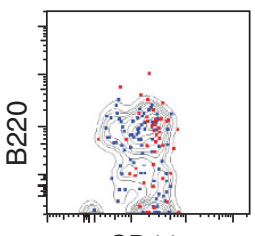

CD11c

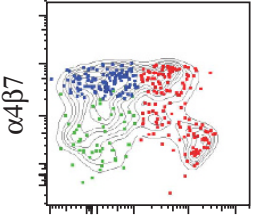

CD103

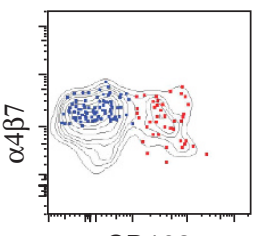

CD103

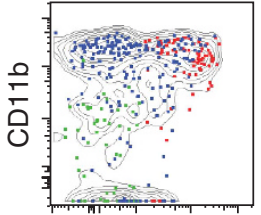

CD103

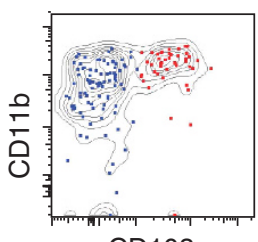

CD103

Figure 4 Small intestine $(\mathrm{SI})$ pre- $\mu \mathrm{DC}$ s are more differentiated than bone marrow (BM) pre- $\mu \mathrm{DCs}$ and have lost potential to give rise to CCR9 ${ }^{+}$ plasmacytoid DCs (pDCs). (a) Surface antigen expression on pre- $\mu$ DCs from the BM, spleen, and SI lamina propia (LP). (b) Pre- $\mu$ DCs were FACS sorted from BM and SI LP and cultured with congenic total BM feeder cells in complete RPMI supplemented with $100 \mathrm{ng} / \mathrm{ml} \mathrm{rFlt} 3 \mathrm{~L}$. Cultures were analyzed by flow cytometry on day 3. Pre- $\mu$ DC-derived subsets are coded as follows: green, CCR ${ }^{+}$; blue, $\alpha 4 \beta 7^{+}$; red, CD103 ${ }^{+}$; gray contour plot indicates total pre$\mu \mathrm{DC}$-derived cells. Data are representative of two experiments with similar results. DC, dendritic cell; Flt3L, Fms-like tyrosine kinase 3 ligand.

leads to reduced circulating retinol, ${ }^{11}$ reduced the number and frequency of pre- $\mu \mathrm{DCs}$ in the BM. Similarly, systemic treatment of mice with the pan-RAR inverse agonist BMS493 reduced pre- $\mu \mathrm{DC}$, whereas intraperitoneal administration of all trans-RA or the RAR $\alpha$ agonist AM580 increased the frequency and number of pre- $\mu$ DCs dramatically. RA regulates hematopoietic progenitor development, and modulation of RARa/RXR signaling regulates hematopoietic stem cell (HSC) differentiation, proliferation, and self-renewal. ${ }^{19-21}$ Furthermore, RA modulates neutrophil differentiation from myeloid progenitors under steady-state conditions. ${ }^{22}$ While BM pre- $\mu$ DCs lack ALDH activity (as indicated by Aldefluor assay; data not shown), subsets of BM hematopoietic cells, including HSCs, express RALDHs, ${ }^{21,23}$ providing a potential source for RA generation from retinol within the local BM environment.

Earlier studies showed that RA regulates cDC function within the intestinal LP and GALT. RA induces the RALDH gene Aldh1a2 in intestinal DCs. ${ }^{10}$ RALDH allows intestinal cDCs to convert retinal to RA, creating a positive feedback loop and also allowing GALT DCs to present RA along with antigen to $\mathrm{T}$ cells. RA in turn induces T-cell expression of the guthoming receptors $\alpha 4 \beta 7$ and CCR9. In this manner, $\mathrm{T}$ cells responding to gut antigens are programmed to traffic back to the intestines. ${ }^{11}$ Interestingly, although RA also induces $\alpha 4 \beta 7$ expression on developing pre- $\mu \mathrm{DCs}$, it does not induce CCR9 expression. Indeed, expression of $\alpha 4 \beta 7$ and CCR9 is mutually exclusive among $\mathrm{B} 220^{+} \mathrm{CD} 11 \mathrm{c}^{\text {int }} \mathrm{DCs}$, and RA actually suppresses the development of CCR9-expressing pDCs in our in vitro and in vivo models. Thus, the signaling pathways that control expression of these trafficking receptors must differ in DCs and lymphocytes. BM pre- $\mu$ DCs do not display intrinsic ALDH activity, but we show that their CD103-expressing cDC progeny upregulate ALDH activity within the gut environment. Furthermore, pre- $\mu D C$-derived splenic $\mathrm{cDC}$ and $\mathrm{CD} 103^{+}$ $\mathrm{CD} 11 \mathrm{~b}^{-}$intestinal $\mathrm{cDC}$ express $\mathrm{CD} 8 \alpha$ in vivo but pre- $\mu \mathrm{DC}-$ derived $\mathrm{CD}_{103}{ }^{+} \mathrm{CDC}$ do not express $\mathrm{CD} 8 \alpha$ in vitro. This suggests that the in vivo tissue environments of the spleen or LP must comprise additional factors or stimuli not present in our in vitro culture system.

We focused primarily on cDC progeny in our analyses, even though pre- $\mu$ DCs rapidly differentiated into $\mathrm{CCR} 9^{+}$pDCs as 
a

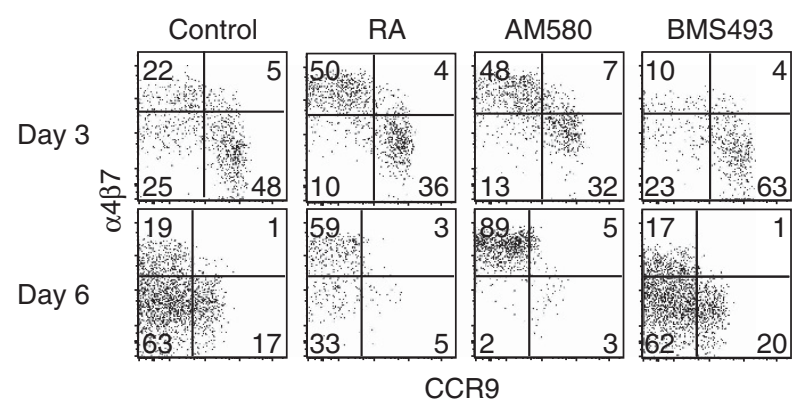

C

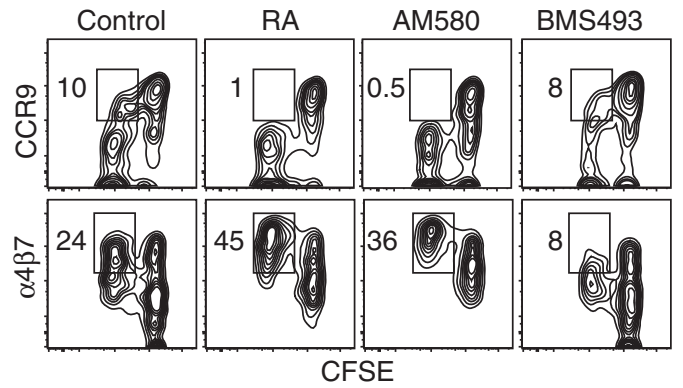

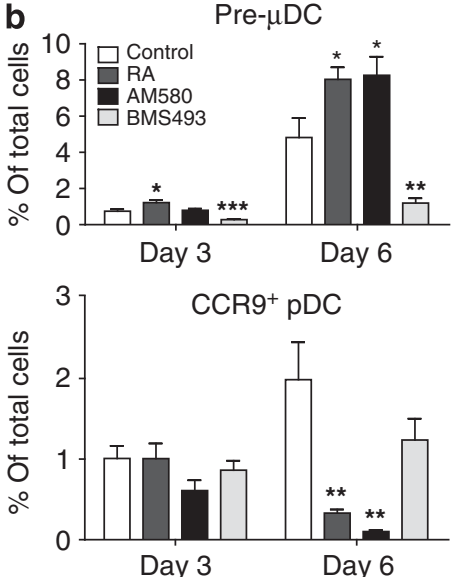

d

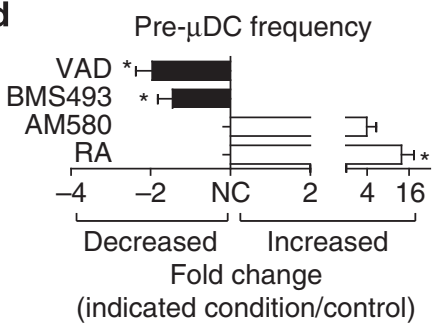

Figure 5 Retinoic acid regulates pre- $\mu \mathrm{DC}$ development in the bone marrow (BM). (a, b) Total BM cells were cultured in complete media supplemented with $100 \mathrm{ng} / \mathrm{ml}$ of Fms-like tyrosine kinase 3 ligand (Flt3L) in the absence (control) or presence of $1 \mathrm{~nm}$ retinoic acid (RA), $10 \mathrm{~nm} \mathrm{AM580} \mathrm{(an} \mathrm{RAR} \alpha$ agonist), or 100 nм BMS498 (a pan-RAR inverse agonist). Cells were harvested on days 3 and 6 and stained for pre- $\mu \mathrm{DC}$ and CCR9 ${ }^{+}$plasmacytoid DC (pDC) markers. (a) Cells were gated on Lin $^{-}$CD11C ${ }^{+}$B220 $^{+}$(Lin indicates CD3, CD19, DX-5, Ter-119, Ly6G). Numbers in each quadrant indicate percent cells. (b) Percent of pre- $\mu \mathrm{DCs}$ (top) and CCR9 ${ }^{+}$pDCs (bottom) on days 3 and 6 in total BM cultures, grown under the conditions described in (a). Data show combined results from four independent experiments with $n=6-8$ for each condition. Error bars show s.e.m.

${ }^{*} P<0.05,{ }^{* *} P<0.01,{ }^{* * *} P<0.001$ compared with control by Student's $t$-test. (c) Total BM cells were labeled with CFSE and cultured as described in (a). Cultures were harvested on day 3 and cells were gated on Lin $^{-} \mathrm{CD}_{11 \mathrm{C}^{+}} \mathrm{B}_{220^{+}}$. Numbers indicate percentage cells. (d) Fold change of pre- $\mu \mathrm{DC}$ frequency in BM from mice treated with each indicated condition compared with control. VAD: vitamin A-deficient mice, $n=10$, control: $n=8$; BMS493/AM580/RA: mice received BMS493 or vehicle (for 7-18 days, $n=4$ each), AM580 or vehicle (4-6 days, $n=2$ ) or RA or vehicle (4-6 days, $n=3$ ). Pre- $\mu \mathrm{DC}$ frequency (among total BM cells) was determined. The fold change in frequency in treated vs. control mice in each paired comparison was calculated, and is shown with s.e.m. or (for AM580) range. ${ }^{*} P<0.05$ by Mann-Whitney test between treated and control mice. DC, dendritic cell.

well both in vitro and in vivo. Pre- $\mu \mathrm{DC}$-derived pDCs were especially abundant relative to pre- $\mu D C$-derived $\mathrm{cDC}$ in the $\mathrm{BM}$ and the IEL compartments of the gut wall of adoptive recipients. This distribution parallels the characteristic homeostatic representation of DC subsets in these sites, where classical $\mathrm{CCR}^{+}{ }^{+}$pDCs significantly outnumber cDCs (whereas cDCs predominate in most other tissues). Although pre- $\mu \mathrm{DC}$ derived pDCs generated in the BM or other tissues can likely home to the gut after upregulation of CCR9, pre- $\mu$ DCs may also be able to generate pDCs locally in the gut after entry from the blood. Importantly, in the gut, pre- $\mu \mathrm{DC}$-derived pDCs appeared rapidly and then disappeared from the recipient IEL compartment within 5-6 days, whereas donor-derived intestinal $\mathrm{CDCs}$ remained readily detectable for at least 10 days after pre- $\mu \mathrm{DC}$ transfer. Overall, the tissue- and time-dependent representation of pre- $\mu \mathrm{DC}$-derived $\mathrm{pDCs}$ and $\mathrm{cDCs}$ likely reflects multiple factors including environmental effects on pre- $\mu \mathrm{DC}$ differentiation into pDCs vs. cDCs, intrinsic and/or environment-specific differences in the survival and proliferation of progeny pDCs vs. cDCs, and a limited self-renewal potential of pre- $\mu$ DCs. Another potential factor is the apparent progressive loss of $\mathrm{pDC}$ potential after pre- $\mu \mathrm{DCs}$ enter peripheral tissues, as evidenced by the inability of pre- $\mu$ DCs from the SI LP to generate pDCs in culture.

In the $\mathrm{BM}$, pre- $\mu \mathrm{DCs}$ are a minor subset of the $\mathrm{B} 220^{+}$ CD11 c ${ }^{\text {int }}$ DCs: The majority of $\mathrm{B}_{22} 20^{+} \mathrm{DCs}$ are CCR9 ${ }^{+}$pDCs and CCR9 ${ }^{-} \alpha 4 \beta 7^{-}$DN DCs. Importantly, DN DCs depleted of pre- $\mu$ DCs gave rise to pre- $\mu$ DCs in culture, and thus contain precursors for both pre- $\mu \mathrm{DC}$ and $\mathrm{CCR}^{+}$pDC. DN DC conversion into $\mathrm{CCR}^{+}{ }^{+} \mathrm{pDC}$ and $\alpha 4 \beta 7^{+}$pre- $\mu \mathrm{DC}$ phenotypes occurred rapidly, within 2 days, and did not require cell division (data not shown). DN DCs also gave rise to $\mathrm{cDCs}$, including $\mathrm{CD} 03^{+} \mathrm{cDCs}$, in longer-term culture. These findings are consistent with the reported ability of splenic and $\mathrm{BM} C D 11 \mathrm{c}^{\text {int }} \mathrm{B} 220^{+} \mathrm{CCR} 9^{-}$DCs to give rise to $\mathrm{CDCs}^{24,25}$ (and see next paragraph). Moreover, culture of classical CD11c ${ }^{-}$CDPs with Flt3L also led to production of DN DCs and pre- $\mu$ DCs, as well as to pDCs and cDCs (data not shown). In the simplest interpretation, our data suggest a linear model in which BM progenitors such as the CDP and possibly early progenitors such as the macrophage, DC progenitor (MDP) give rise to $\mathrm{CD} 11 \mathrm{c}^{\mathrm{int}} \mathrm{B} 220^{+} \mathrm{DN}$ DCs, which in turn differentiate into pre- $\mu \mathrm{DCs}$ that rapidly exit the marrow and home to the gut to replenish intestinal DCs (Supplementary 
Figure S5 online). However, given the emerging appreciation of nonlinear developmental sequences in hematopoiesis and of the malleability of progenitors in response to environmental signals, ${ }^{25-27}$ we cannot exclude other pathways to pre- $\mu \mathrm{DC}$ development.

The gut-homing ability of pre- $\mu \mathrm{DC}$, their capacity to differentiate into $\mathrm{pDC}$ as well as $\mathrm{CDC}$, and their preferential contribution to intestinal DC distinguishes them from other migratory DC precursors. BM pre-cDCs (lineage ${ }^{-}$B220 ${ }^{-}$ $\mathrm{CD}_{11 \mathrm{c}^{+}} \mathrm{MHCII}^{-} \mathrm{CD} 135^{+}$Sirp $\alpha^{\text {low }}$ cells) described by Liu et al. $^{28}$ and splenic pre-cDC $\left(\mathrm{CD} 11 \mathrm{c}^{\text {int }} \mathrm{MHCII}^{-} \mathrm{CD} 45 \mathrm{RA}{ }^{\text {low }}\right.$ CD $43^{\text {int }}$ Sirp $\alpha^{\text {int }}$ ) described by Naik et al. ${ }^{29}$ have a more restricted developmental potential, contributing to peripheral $\mathrm{cDCs}$ but not $\mathrm{pDCs}$. Moreover, although pre-cDCs give rise to $\mathrm{CD}_{103}{ }^{+}$intestinal DCs as well as other peripheral DC populations, they lack specialized gut-homing ability (they are $\alpha 4 \beta 7$ and CCR9 negative). In fact, in our co-transfer experiments, pre- $\mu \mathrm{DC}$ are 7 - to 10 -fold better than pre-cDC at contributing to intestinal $\mathrm{cDC}$ on a per cell basis. Pre- $\mu \mathrm{DC}$ are more closely related phenotypically to recently identified "CCR9 ${ }^{-}$pDC-like precursors," a common DC precursor which (like pre- $\mu \mathrm{DC}$ and the DN DC population studied here) is $\mathrm{B} 220^{+}$and expresses intermediate levels of CD11c: Schlitzer et $a l^{25,30}$ showed elegantly that although these CCR9 ${ }^{-}$pDC precursors can be induced to differentiate into cDC by GM-CSF or microenvironmental influences, they preferentially give rise to pDCs. This contrasts with the preferential cDC development displayed by pre- $\mu$ DCs. Phenotypically, CCR9 ${ }^{-}$pDC precursors are defined as SiglecH ${ }^{\text {hi }}$ PDCA $1^{\text {hi }}$ CCR9 ${ }^{-}$CD11c ${ }^{+}$ and $\mathrm{B} 220^{+} ; 25,30$ as such they comprise a small subset of pre$\mu D C$ (the PDCA $1{ }^{\text {hi }}$ Siglec $H^{\text {hi }}$ fraction), as well as a large fraction of DN DCs enriched for high levels of expression of the pDC differentiation antigens PDCA1 and SiglecH. We have shown that, in contrast to pre- $\mu$ DC but similar to Schlitzer's pDC precursors, CCR $9^{-} \alpha 4 \beta 7^{-}$DN DCs preferentially give rise to pDCs at early time points. We propose therefore that the $\mathrm{Lin}^{-} \mathrm{B} 220^{+} \mathrm{C} 11 \mathrm{c}^{\text {int }} \mathrm{CCR} 9^{-}$population of BM cells comprises a diverse precursor pool for peripheral DC subsets, in which functional precursors with a preference towards $\mathrm{pDC}$ development are enriched in the PDCA $1^{\text {hi }}$ SiglecH ${ }^{\text {hi }} \alpha 4 \beta 7^{-}$CCR9 ${ }^{-}$ pDC-like subset; whereas precursors biased towards development into intestinal $\mathrm{CD}_{103}{ }^{+} \mathrm{DCs}$ are enriched in the guthoming $\alpha 4 \beta 7^{\text {hi }}$ pre- $\mu D C$ population. Indeed, pre- $\mu D C$ themselves may well be heterogeneous in potential: we cannot exclude the possibility that some pre- $\mu \mathrm{DC}$ are clonally committed to pDC vs. cDC development, or indeed that $\mathrm{B} 220^{+} \mathrm{C} 11 \mathrm{c}^{\text {int }} \mathrm{BM} \mathrm{DC}$, including gut-tropic pre- $\mu \mathrm{DC}$, are composed of distinct subsets of committed pDC vs. cDC precursors. This pool of $\mathrm{B} 220+$ DC precursors was not recognized in earlier studies that included B220 as a marker of exclusion in a "lineage negative" sort gate. ${ }^{28}$ In the BM, pre$\mu \mathrm{DC}$ are a minor subset of this pool, which may reflect programming for rapid exit from the marrow to seed the gut wall. In addition to these $\mathrm{CD} 11 \mathrm{c}^{+}$migratory precursors, earlier progenitors, including $\mathrm{CD} 11 \mathrm{c}^{-} \mathrm{CDPs}$ and even pluripotent HSCs, may be able to seed peripheral tissues and contribute to tissue DC populations. ${ }^{31,32}$ The rates of generation and exit of each of these distinctive DC precursors, their relative contributions to $\mathrm{CD}_{103}{ }^{+} \mathrm{CD} 11 \mathrm{~b}^{-}$vs. $\mathrm{CD} 103^{+} \mathrm{CD} 11 \mathrm{~b}^{+}$intestinal DC and to other peripheral DC populations, and their relative importance in homeostatic vs. inflammatory settings remain to be determined.

The recruitment of blood leukocytes requires adhesion and chemoattractant receptors to mediate endothelial adhesion, arrest, and subsequent diapedesis. ${ }^{33}$ Pre- $\mu$ DCs express $\alpha 4 \beta 7$, an integrin receptor for the mucosal vascular addressin MAdCAM1, on gut postcapillary venules, and blockade of $\alpha 4 \beta 7$ prevents pre- $\mu$ DCs from contributing to intestinal DC populations. It is unclear which chemoattractant receptors are involved in this process. CCR9 is an important chemokine receptor for $\mathrm{T}$ and $\mathrm{B}$ lymphocytes and in $\mathrm{CCR}{ }^{+}{ }^{+} \mathrm{pDC}$ homing to the SI. However, pre- $\mu$ DCs do not express CCR9. Moreover, blocking antibody to the CCR9 ligand CCL25 had no effect on pre- $\mu D C$-derived $c D C$ in the SI, and pre- $\mu$ DCs from CCR9knockout mice homed to and gave rise to $\mathrm{CD}_{103}{ }^{+} \mathrm{cDCs}$ in the SI as efficiently as wild-type cells (data not shown). Although BM pre- $\mu$ DCs express minimal CCR6, CCR6 is upregulated on pre- $\mu \mathrm{DC}$ in the SI LP, thus CCR6 might contribute to pre- $\mu \mathrm{DC}$ homing. Pre- $\mu$ DCs also express CCR5 and CXCR3 that could participate in gut homing. On the other hand, pre- $\mu \mathrm{DC}$ lack the lymphoid organ trafficking receptor CCR7, consistent with their inability to home well to MLNs in spite of $\alpha 4 \beta 7$ expression.

In conclusion, we identify a gut homing common DC precursor whose development in BM is regulated by RA and impaired in vitamin A deficiency. Pre- $\mu$ DCs can generate $c D C$ and $\mathrm{CCR}^{+}{ }^{+} \mathrm{pDC}$, but more efficiently give rise to $\mathrm{CD} 103^{+}$ cDC populations in the small intestines. Gut-specific homing of DC precursors may allow targeted replacement of intestinal DCs as a function of ongoing tissue-specific immune requirements.

\section{METHODS}

Mice. C57Bl/6.CD45.2 (B6.CD45.2) and C57Bl/6.CD45.1 (B6.CD45.1) mice were originally purchased from Jackson Laboratory (Bar Harbor, $\mathrm{ME}$ ) and were maintained and bred in specific pathogen-free conditions in the animal facility in Veterans Affairs Palo Alto Health Care Systems (VAPAHCS). To generate B16/Flt3L-injected mice, 5 million B16/Flt3L cells were injected subcutaneously near the neck and animals were killed 11-14 days later. All animals were used in accordance with the guidelines set forth by the animal committee of VAPAHCS. Vitamin A-deficient and control mice were generated as described. ${ }^{11}$ In some experiment, mice were i.p. injected with BMS493 ( $25 \mathrm{~mm}$ in DMSO) at $1 \mu \mathrm{l} / \mathrm{g}$ of weight in $25 \mu \mathrm{l}$ of olive oil. Control animals received the same amount of DMSO in olive oil. All trans-RA was made into suspension in olive oil at $25 \mathrm{mg} / \mathrm{ml}$ and injected i.p. at $125 \mu \mathrm{g} / \mathrm{g}$ of weight, control animals received olive oil. AM580 was dissolved in DMSO at a concentration of $40 \mathrm{mg} / \mathrm{ml}$ and injected i.p. at $1 \mu \mathrm{l} / \mathrm{g}$ of weight with $100 \mathrm{ml}$ of olive oil; control animals received the same amount of DMSO in olive oil.

Flow cytometry. Samples (single-cell suspensions) were first blocked with FACS buffer (HBSS with $2 \%$ FCS) containing $100 \times$ dilution of antibody against mouse Fc $\gamma$ III/II receptor (BD Bioscience, San Jose, $\mathrm{CA})$ and rat serum to prevent nonspecific binding of monoclonal antibodies. The following antibodies were used for staining: CD3- 
PECy7/CD3-Biotin/CD3-PerCpCy5.5 (145-2C11), CD19-PECy7/ CD19-biotin/CD19-PerCPCy5.5 (ID3), NK1.1-PECy7/NK1.1-biotin/ NK1.1-PerCPCy5.5 (PK136), CD49b-Biotin(DX-5), Ly6G-Biotin (1A8), Ter-119(Ter-119), B220-PECy7/B220-Biotin/B220-PerCPCy5.5 (RA3-6B2), MHCII-AF700(M5/114.15.2)/MHCII-Biotin (2G9), CD11c-PB (N418), $\alpha 4 \beta 7-A P C / \alpha 4 \beta 7-\mathrm{PE}$ (DATK32), CCR9-APC/ CCR9-PE/CCR9-FITC (242503), CCR9-PECy7 (CW1.1), CD103PE(M290), CD11b-AF700 (M1/70), CD8 $\alpha$-PE (53-6.7), CD45.1PerCPCy5.5/CD45.1-APC, CD45.2-FITC/CD45.2-PerCPCy5.5 (RA36B2), CD135-PE/CD135-PECy5 (A2F10), CD115-APC/CD115-FITC (AFS98), CD117-PECy7 (2B8), PDCA1-FITC/PDCA1-PerCPeFluor710(927), SiglecH-FITC (eBio440C), Ly6C-FITC(AL-21), CD4AF700(RM4-5), CD9-AF647 (MZ3), Sirp $\alpha$-FITC/Sirp $\alpha$-PerCPeFluor710 (P84), $\alpha 4$-PE (9C10, BD), $\beta 1$-PECy7 (HMb1-1, eBioscience, San Diego, CA), $\alpha$ V-PE (RMV-7, BD Bioscience), $\beta 3$-PE(2C9.G2, BD Bioscience), CD62L-FITC (MEL14), CXCR3-APC (CXCR3-173, Biolegend, San Diego, CA), CCR2-APC (475301, R\&D), CCR5-PE (2D7/CCR5, BD Bioscience), CCR7-APC(4B12, eBioscience), CXCR5-PE (BD, 2G8) and CCR6-PE (140706, R\&D, Minneapolis, $\mathrm{MN})$.

Cell isolation from tissues. Femurs and tibias were collected and crushed using a $5-\mathrm{ml}$ syringe. Bone fragments were removed by filtering through a wire mesh to isolate BM cells.

Spleens, inguinal, auxiliary, and brachial lymph nodes (LNs) were isolated and digested with RPMI media containing 5\% FCS, $500 \mathrm{unit} / \mathrm{ml}$ of collagenase IV (Worthington Biochemical, Lakewood, NJ) and $1 \mathrm{unit} / \mathrm{ml}$ of DNaseI (Sigma, St Louis, MO) for $30 \mathrm{~min}$ at $37^{\circ} \mathrm{C}$ and made into single-cell suspension.

Lungs were perfused with $25 \mathrm{ml}$ of phosphate-buffered saline (PBS) and cut into small pieces $(\sim 1-2 \mathrm{~mm})$ and digested as were spleen and LNs.

Full-length SI (with Peyer's Patches removed) was cut open longitudinally and rinsed twice in HBSS (without $\mathrm{Ca}^{2+}$ and $\mathrm{Mg}^{2+}$ ) with $2 \%$ FCS and cut into small pieces. To isolate IEL, the cut SI was incubated twice in $10 \mathrm{ml}$ of $2 \%$ HBSS containing $15 \mathrm{mg} / 100 \mathrm{ml}$ dithiothreitol at $37^{\circ} \mathrm{C}$ for $20 \mathrm{~min}$, twice, and supernatant containing IEL was collected after each incubation. Residual tissues were digested in $10 \mathrm{ml}$ RPMI containing $5 \%$ FCS and $0.5 \mathrm{mg} / \mathrm{ml}$ of collagenase IV (Sigma $\mathrm{C} 2139$ ) at $37^{\circ} \mathrm{C}$ for $30 \mathrm{~min}$, three times. Supernatant containing LP cells was collected. Mononucleated cells from the IEL and LP supernatant were isolated by gradient separation with 40 and $75 \%$ percoll solutions (GE, Pittsburgh, PA, 17-0891-01) at 2,000 RPMI for $20 \mathrm{~min}$ at room temperature. Cells of interest were located at the interface. When young mice (10-16 days of age) were used, Peyer's Patches were not removed because they are not clearly visible at this age.

Cell sorting. To sort pre- $\mu$ DCs and DN DCs from normal and Flt3Ltreated mice, BM cells were isolated as described above and enriched by magnetic-activated cell sorting using the pan-DC kits from Miltenyi (Auburn, CA). The cells were then sorted on Aria II or III (BD) for Lineage (CD3, CD19, NK1.1)-CD11 $\mathrm{c}^{\text {int }} \mathrm{B} 220^{+} \alpha 4 \beta 7^{+} \mathrm{CCR}^{-}$pre$\mu \mathrm{DC}$ and Lineage ${ }^{-} \mathrm{CD} 11 \mathrm{c}^{\mathrm{int}} \mathrm{B} 220^{+} \alpha 4 \beta 7^{-} \mathrm{CCR}^{-}$DN DC.

Adoptive transfer. For transfer into lethally irradiated recipients, B6.CD45.1/45.2 F1 mice were given full-body irradiation with a lethal dose of 900 rads total from a 131 Cs source at two doses ( $4 \mathrm{~h}$ apart, 450 rads each). Irradiated mice were given total BM (CD45.1) and sorted pre- $\mu$ DCs (CD45.2 or vice versa) at a ratio of 10:1 (5 $\times 10^{6}$ total $\mathrm{BM}$ and $0.5 \times 10^{6}$ sorted pre- $\left.\mu \mathrm{DC}\right)$. Mice were kept on antibiotic water until they were killed on days $4,7,10$, or 14 . Adoptive transfer into normal recipients was performed the same way except recipient mice were not irradiated and received only sorted pre- $\mu \mathrm{DC}\left(1-3 \times 10^{6}\right)$. For homing experiments, $3 \times 10^{6}$ sorted pre- $\mu$ DCs were transferred into each congenic recipient.

Blocking experiments. Sorted pre- $\mu \mathrm{DC}$ from Flt3L-treated mice were pre-blocked with $250 \mu \mathrm{g}$ of anti- $\alpha 4 \beta 7$ antibody made in house (DATK32) or isotype control (Rat IgG2a) in $200 \mathrm{ml} \mathrm{PBS} \mathrm{for} 10 \mathrm{~min}$ at room temperature before injection. Subsequently, recipients received blocking antibody or isotype control every $12 \mathrm{~h}$ via intraperitoneal injection until mice were killed. All cell transfers were done via retroorbital injection.

In vitroculture. Pre- $\mu \mathrm{DCs}$ and DN DCs were sorted from BM (or SI LP for pre- $\mu \mathrm{DC}$ in some experiments) from normal or Flt3L-treated mice and cultured with congenic total BM cells at a density of 3-5 million cells $/ \mathrm{ml}, 200 \mu \mathrm{l} /$ well in flat-bottom 96 -well plate in complete RPMI media (10\% FCS, $1 \times$ penicillin/streptomycin) supplemented with $100 \mathrm{ng} / \mathrm{ml}$ recombinant Flt3L. Media were changed on day 3.

Total BM cells were cultured in complete media with normal FCS or delipidated FCS with $100 \mathrm{ng} / \mathrm{ml}$ of rFlt3L in the presence of $1 \mathrm{nM}$ of ATRA, $10 \mathrm{~nm}$ of AM580, or $100 \mathrm{~nm}$ of BMS493. Media were changed on day 3 .

CFSE labeling. Total BM cells were incubated with $1 \mu \mathrm{M}$ of CFSE at a density of $10 \mathrm{E} 6 \mathrm{cells} / \mathrm{ml}$ in PBS for $10 \mathrm{~min}$ at $37^{\circ} \mathrm{C}$ and washed by incubating in complete media for $5 \mathrm{~min}$ at $37^{\circ} \mathrm{C}$.

Analysis of ALDH activity. ALDH activity in each cell was analyzed using Aldefluor Staining Kit (StemCell Technologies, Vancouver, BC, Canada) as per the manufacturer's protocol with modifications as previously described. ${ }^{18}$ Briefly, cells were suspended in Aldefluor assay buffer containing activated substrate $(150 \mathrm{nM})$ with or without the ALDH inhibitor DEAB $(100 \mu \mathrm{M})$ at a density of $10 \mathrm{E} 6 \mathrm{cells} / \mathrm{ml}$ and incubated in $37^{\circ} \mathrm{C}$ water bath for $30 \mathrm{~min}$. Subsequent surface antigen staining was performed in Aldefluor assay buffer. Cells were immediately analyzed on LSRII analyzer (BD) without fixing.

Statistical analysis. The statistical significance of differences between the two sets of data was assessed by Student's $t$-test unless stated otherwise.

SUPPLEMENTARY MATERIAL is linked to the online version of the paper at http://www.nature.com/mi

\section{ACKNOWLEDGEMENTS}

We thank L. Rott for assistance with flow cytometry and cell sorting and W.W. Agace for critical comments on early studies. The B16 melanoma cell line stably transfected with murine Flt3L was a kind gift from G. Dranoff, Dana-Farber Cancer Institute, Boston, MA, USA. R.Z. is a recipient of the National Science Scholarship awarded by the Agency for Science, Technology And Research, Singapore; C.O. was supported by the Wenner-Gren Foundation, and by a Research Fellowship Award (\#2791) from the Crohn's \& Colitis Foundation of America; R.Y. was supported by the Immunology training Grant (5 T32 Al07290, Molecular and Cellular Immunobiology); M.L. is a recipient of a senior fellowship from the Crohn's and Colitis Foundation, and was a fellow under the NIH Training Grant Al07290; H.H. is a recipient of an Investigator Career Award from the Arthritis Foundation and was a fellow under the NIH Training Grant AI07290; A.H. was supported by NIH Grant DK085426. The work was supported in part by NIH Grants Al047822, Al093981, and DK084647 to E.C.B., the FACS Core facility of the Stanford Digestive Disease Center under DK056339, and a Merit Award from the Department of Veterans Affairs.

\section{AUTHOR CONTRIBUTIONS}

R.Z. designed and performed the experiments and wrote the manuscript; C.O. carried out early phenotypic and other studies that led to the definition of pre- $\mu \mathrm{DC}$, and performed the homing studies; R.Y. and M.L. performed the experiments; H.H. was involved in the initiation of the project, including initial studies of pre- $\mu \mathrm{DC}$ development, and provided advice; A.H. assisted with the homing study and provided advice; E.C.B. directed the study and wrote the manuscript. All authors reviewed and commented on the manuscript.

\section{DISCLOSURE}

The authors declared no conflict of interest.

c 2013 Society for Mucosal Immunology 


\section{REFERENCES}

1. Annacker, O. et al. Essential role for CD103 in the Tcell-mediated regulation of experimental colitis. J. Exp. Med. 202, 1051-1061 (2005).

2. Bogunovic, M. et al. Origin of the lamina propria dendritic cell network. Immunity 31, 513-525 (2009).

3. Iwasaki, A. Mucosal dendritic cells. Annu. Rev. Immunol. 25, 381-418 (2007).

4. Johansson-Lindbom, B. et al. Functional specialization of gut CD103+ dendritic cells in the regulation of tissue-selective T cell homing. J. Exp. Med. 202, 1063-1073 (2005).

5. Silva, M.A. Intestinal dendritic cells and epithelial barrier dysfunction in Crohn's disease. Inflamm. Bowel Dis. 15, 436-453 (2009).

6. Salazar-Gonzalez, R.M. et al. CCR6-mediated dendritic cell activation of pathogen-specific Tcells in Peyer's patches. Immunity 24, 623-632 (2006).

7. Varol, C. et al. Intestinal lamina propria dendritic cell subsets have different origin and functions. Immunity 31, 502-512 (2009).

8. Coombes, J.L. et al. A functionally specialized population of mucosal CD103 + DCs induces Foxp3 + regulatory T cells via a TGF-beta and retinoic acid-dependent mechanism. J. Exp. Med. 204, 1757-1764 (2007).

9. Geissmann, F., Manz, M.G., Jung, S., Sieweke, M.H., Merad, M. \& Ley, K. Development of monocytes, macrophages, and dendritic cells. Science 327, 656-661 (2010).

10. Jaensson-Gyllenback, E. et al. Bile retinoids imprint intestinal CD103+ dendritic cells with the ability to generate gut-tropic T cells. Mucosal Immunol. 4, 438-447 (2011).

11. Iwata, M., Hirakiyama, A., Eshima, Y., Kagechika, H., Kato, C. \& Song, S.Y. Retinoic acid imprints gut-homing specificity on T cells. Immunity $\mathbf{2 1}$ 527-538 (2004).

12. Hill, J.A. et al. Retinoic acid enhances Foxp3 induction indirectly by relieving inhibition from CD4 + CD44hi Cells. Immunity 29, 758-770 (2008).

13. Berlin, C. et al. Alpha 4 beta 7 integrin mediates lymphocyte binding to the mucosal vascular addressin MAdCAM-1. Cell 74, 185-195 (1993).

14. Mach, N., Gillessen, S., Wilson, S.B., Sheehan, C., Mihm, M. \& Dranoff, G. Differences in dendritic cells stimulated in vivo by tumors engineered to secrete granulocyte-macrophage colony-stimulating factor or Flt3-ligand. Cancer Res. 60, 3239-3246 (2000).

15. Edelson, B.T. et al. Peripheral CD103 + dendritic cells form a unified subset developmentally related to CD8alpha + conventional dendritic cells. J. Exp. Med. 207, 823-836 (2010).

16. Agace, W.W. \& Persson, E.K. How vitamin A metabolizing dendritic cells are generated in the gut mucosa. Trends Immunol. 33, 42-48 (2012).

17. Schulz, O. et al. Intestinal CD103 + , but not CX3CR1 + , antigen sampling cells migrate in lymph and serve classical dendritic cell functions. J. Exp. Med. 206, 3101-3114 (2009).
18. Yokota, A. et al. GM-CSF and IL-4 synergistically trigger dendritic cells to acquire retinoic acid-producing capacity. Int. Immunol. 21, 361-377 (2009).

19. Chute, J.P., Ross, J.R. \& McDonnell, D.P. Minireview: Nuclear receptors, hematopoiesis, and stem cells. Mol. Endocrinol. 24, 1-10 (2010).

20. Safi, R. et al. Pharmacological manipulation of the RAR/RXR signaling pathway maintains the repopulating capacity of hematopoietic stem cells in culture. Mol. Endocrinol. 23, 188-201 (2009).

21. Chute, J.P. et al. Inhibition of aldehyde dehydrogenase and retinoid signaling induces the expansion of human hematopoietic stem cells. Proc. Natl. Acad. Sci. USA 103, 11707-11712 (2006).

22. Kastner, P. \& Chan, S. Function of RARalpha during the maturation of neutrophils. Oncogene 20, 7178-7185 (2001).

23. Hess, D.A. et al. Functional characterization of highly purified human hematopoietic repopulating cells isolated according to aldehyde dehydrogenase activity. Blood 104, 1648-1655 (2004).

24. Segura, E., Wong, J. \& Villadangos, J.A. Cutting edge: B220 + CCR9dendritic cells are not plasmacytoid dendritic cells but are precursors of conventional dendritic cells. J. Immunol. 183, 1514-1517 (2009).

25. Schlitzer, A. et al. Identification of CCR9- murine plasmacytoid DC precursors with plasticity to differentiate into conventional DCs. Blood 117, 6562-6570 (2011)

26. Watowich, S.S. \& Liu, Y.J. Mechanisms regulating dendritic cell specification and development. Immunol. Rev. 238, 76-92 (2010).

27. Franco, C.B., Chen, C.C., Drukker, M., Weissman, I.L. \& Galli, S.J. Distinguishing mast cell and granulocyte differentiation at the single-cell level. Cell Stem. Cell 6, 361-368 (2010).

28. Liu, K. et al. In vivo analysis of dendritic cell development and homeostasis. Science 324, 392-397 (2009).

29. Naik, S.H. et al. Intrasplenic steady-state dendritic cell precursors that are distinct from monocytes. Nat. Immunol. 7, 663-671 (2006).

30. Schlitzer, A. et al. Tissue-specific differentiation of a circulating CCR9pDC-like common dendritic cell precursor. Blood 119, 6063-6071 2012).

31. Schmid, M.A., Takizawa, H., Baumjohann, D.R., Saito, Y. \& Manz, M.G. Bone marrow dendritic cell progenitors in mice sense pathogens via Tolllike receptors and subsequently migrate to inflamed lymph nodes. Blood 118, 4829-4840 (2011).

32. Massberg, S. et al. Immunosurveillance by hematopoietic progenitor cells trafficking through blood, lymph, and peripheral tissues. Cell 131, 994-1008 (2007).

33. Butcher, E.C. Leukocyte-endothelial cell recognition: three (or more) steps to specificity and diversity. Cell 67, 1033-1036 (1991). 